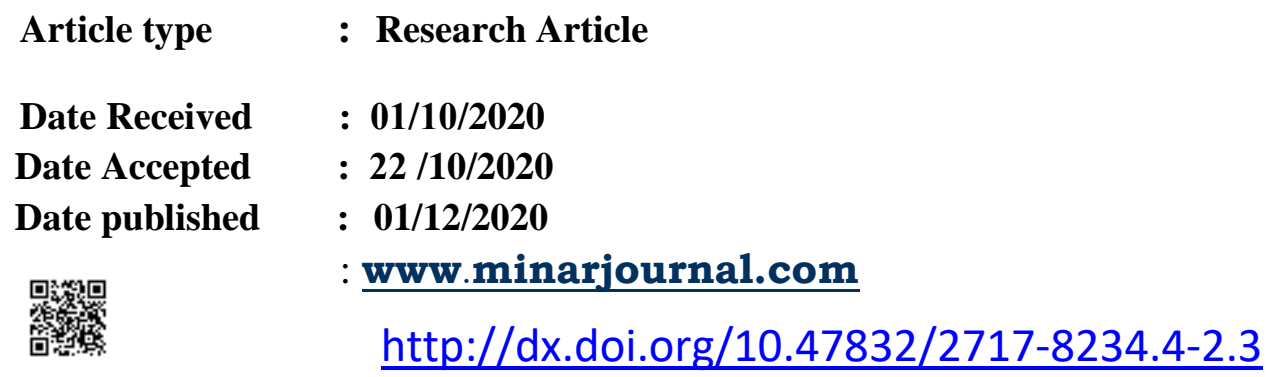

\title{
INVESTIGATION OF ELECTRONS DIFFUSION COEFFICIENT DEPENDENCE ON TEMPERATURE IN PLASMA GAS CO2, N2, HE AND MIXTURES
}

\section{Nisaan Saud ORAIBI ${ }^{1}$}

\begin{abstract}
The evolution of the $\mu$ Nth value at different temperatures was achieved through the drift velocity of electron. The results were show when the temperature was increased, the number of the electrons will be decreased because using the momentum transfer cross section for $\mathrm{CO} 2$ molecules through collisions. The calculation of the diffusion coefficient was used to deduce the $\mu$ Nth values of $\mathrm{CO} 2$ electrons at temperature between 288 to $573 \mathrm{k}$ by utilization numerically the Boltzmann equation solution. The results were appearing the agreement with the theoretical and experimental data.
\end{abstract}

Keywords: Diffusion Coefficients, Boltzmann Equation, Swarms Parameters, Energy Distribution Function.

\footnotetext{
${ }^{1}$ Al-Nahrain University, Iraq, Nissan.oribi@ced.nahrainuniv.edu.iq, https://orcid.org/0000-0001-8484-1162
}

This article has been scanned by iThenticat No plagiarism detected

Copyright $\odot$ Published by Minar Journal, www.minarjournal.com 


\section{Introduction}

The electron energy distribution was performing the evaluation of momentum transfer cross section through the drift velocity measurement. For $\mathrm{CO}, \mathrm{CO} 2, \mathrm{H} 2 \mathrm{O}$ and $\mathrm{NH} 3, \ldots$ etc. were found that the electron drift velocity was linearly changing with the lowest of $E / N$ ( where $E / N$ is the applied electric field strength to the total gas number density, $\mathrm{V}_{\mathrm{cm}}$ 2) and also the electrons distribution function was Maxwellian changing as a function of the temperature oT, and then the value of $\mu \mathrm{N}$ was obtained, since $\mu$ represents the electron mobility in unit of (cm2 sec-1 V-1) at small value of $\mathrm{E} / \mathrm{N}$ for many[1-3]. Therefore, at the temperatures between 193 and 573 Kelvin, electron drift velocity values had be brought out that $\mu$ Nth values were decreasing when the temperature was increased according to the above when using the momentum transfer cross section $\sigma \mathrm{m}$ to calculate the electron mobility $\mu$ from below forma, then there is the conflicting trend for the expected, which is $[3,4]$ :

$\mu \mathrm{N}_{\mathrm{th}}=-\left(\frac{2}{\mathrm{~m}}\right)^{1 / 2} \frac{\mathrm{e}}{3} \int_{0}^{\infty} \frac{\epsilon}{\sigma_{\mathrm{m}}} \frac{\mathrm{df}_{\mathrm{M}}(\epsilon)}{\mathrm{d} \epsilon} \mathrm{d} \epsilon$

where $\sigma \mathrm{m}$ represent the momentum transfer cross section $(\mathrm{cm} 2), \mathrm{fM}(\varepsilon)$ represents the Maxwellian energy distribution function, $\varepsilon$ is the electron energy $(\mathrm{eV})$, e and $\mathrm{m}$ are the electric charege, $1.6 \times 10-19$ coulomb and $\mathrm{m}$ represent the electron mass $9.109 \times 10-28 \mathrm{gm}$. Equation (1) was showing the performance of $\mathrm{CO} 2$ lasers because the electron scattering cross section from $\mathrm{CO} 2$ molecules. The collision by $\mathrm{CO} 2$ molecules in the first vibrational state with total momentum transfer cross section could be leads to the difference in the theoretical and experimental data for $\mu \mathrm{N}$ th values against temperature oT [1-4]. This a large temperature, are extrapolate to $\mathrm{E} / \mathrm{N}=0$ at $573 \mathrm{~K}$ for the electron drift velocity, this mean, at thermal equilibrium with $\mathrm{CO} 2$ molecules, any one could be obtain the electron swarm parameter, which is $\mu$ Nth value [5]. By measuring the coefficient of thermal electrons diffusion through the alternative experimental method was obtained the $\mu N$ th value but this value changes with oT, and by using the Nernst-Townsend or Einstein formula, we can find [6]:

$\mu \mathrm{N}_{\text {th }}=\mathrm{ND}_{\text {th }} \frac{\mathrm{e}}{\mathrm{kT}}$

Where Dth is represent the coefficient of the electrons diffusion, and $\mathrm{k}$ is represent the Boltzmann constant, $1.380662 \times 10-23 \mathrm{~J} / 0 \mathrm{~K}$, this work was achieved in the present work.

\section{Computational procedures of Boltzmann equation:}

The main purpose of Boltzmann transport equation solution was to obtain the electron distribution function $f(r, c, t)$ volume part $d r d c$ in the locus $r$ with spatial velocity $C$, which is $f(r, c, t) d r d c[6,7]$. The electrons distribution in energy, the number of electrons in the volume element $\mathrm{dr} d \mathrm{~d}$ in position $\mathrm{r}$ and velocity $\mathrm{C}$ space and time have important role in the electron's collisions with pure gas and/or mixture gases [3]. Consider the function $f$ was detachable which:

$\mathrm{f}=\mathrm{n}(\mathrm{r}, \mathrm{t}) \mathrm{F}_{\mathrm{o}}(\epsilon)$

Whereas $\mathrm{n}$ is total electron gas number density as a function of the space and time, Fo refers to the electron distribution as a function of the energy $\epsilon$. if the diffusion of electron was omitted in analogy to the drift velocity then Fo is was not depend on $r$ in this case. Furthermore, in the time-of-flight experiment the distribution function Fo was not depend on $t$ was too right. The Boltzmann transport equation was whereupon, yielding that the function Fo was $[8,9]$

$\frac{\mathrm{d}}{\mathrm{d} \epsilon}\left(\frac{\mathrm{e}^{2} \mathrm{E}^{2} \epsilon}{3 \mathrm{~N} \mathrm{Q}_{\mathrm{m}}(\epsilon)} \frac{\mathrm{d}}{\mathrm{d} \epsilon} \mathrm{F}_{\mathrm{o}}(\epsilon)\right)+\frac{2 \mathrm{~m}}{\mathrm{M}} \frac{\mathrm{d}}{\mathrm{d} \epsilon}\left(\epsilon^{2} \mathrm{NQ}_{\mathrm{m}}(\epsilon) \mathrm{F}_{\mathrm{o}}(\epsilon)+\mathrm{kT} \frac{\mathrm{d}}{\mathrm{d} \epsilon} \mathrm{F}_{\mathrm{o}}(\epsilon)\right)+$
$\sum_{\mathrm{j}}\left[\left(\epsilon+\epsilon_{\mathrm{j}}\right) \mathrm{F}_{\mathrm{o}}\left(\epsilon+\epsilon_{\mathrm{j}}\right) N \mathrm{Q}_{\mathrm{j}}\left(\epsilon+\epsilon_{\mathrm{j}}\right)-\epsilon \mathrm{F}_{\mathrm{o}}(\epsilon) \mathrm{NQ}_{\mathrm{j}}(\epsilon)\right]+\sum_{\mathrm{j}}\left[\left(\epsilon-\epsilon_{\mathrm{j}}\right) \mathrm{F}_{\mathrm{o}}\left(\epsilon-\epsilon_{\mathrm{j}}\right) N \mathrm{Q}_{-\mathrm{j}}\left(\epsilon-\epsilon_{\mathrm{j}}\right)-\epsilon \mathrm{F}_{\mathrm{o}}(\epsilon) \mathrm{NQ}_{-\mathrm{j}}(\epsilon)\right]=0$ (4)

Whereas e and $m$ are the electronic charge and electron mass respectively, $E$ represent the electric field strength, $\mathrm{Vcm}-1, \mathrm{~N}$ is the total gas number density, $\mathrm{cm}-3, \mathrm{Qm}$ is the momentum collision cross-section for the electron-atom reaction, $\epsilon$ is the energy of the electron, $\mathrm{eV}, \mathrm{Qj}(\epsilon)$ represent the excitation cross section for the energy loss at the jth level, and $\mathrm{Q}-\mathrm{j}(\epsilon)$ represent the de-excitation cross section for the energy gain at the jth level. 
The defining of the normalization of the energy distribution which is:

$\int_{0}^{\infty} \epsilon^{\frac{1}{2}} \mathrm{~F}_{\mathrm{o}}(\epsilon) \mathrm{d} \epsilon=1$

This mean, the number of the electron in the velocity spatial is equal unity.

$$
\frac{\partial \mathrm{n}}{\partial \mathrm{t}}=\mathrm{D}_{\mathrm{o}}\left(\frac{\partial^{2} \mathrm{n}}{\partial \mathrm{x}^{2}}+\frac{\partial^{2} \mathrm{n}}{\partial \mathrm{y}^{2}}\right)-\mathrm{V}_{\mathrm{o}} \frac{\partial \mathrm{n}}{\partial \mathrm{z}}+\mathrm{D}_{\mathrm{o}} \frac{\partial^{2} \mathrm{n}}{\partial \mathrm{z}^{2}}
$$

From equation (4) the drift velocity, Vo was represented by:

$\mathrm{V}_{\mathrm{o}}=-\frac{\mathrm{E}}{3}\left(\frac{2 \mathrm{e}}{\mathrm{m}}\right)^{\frac{1}{2}} \int_{0}^{\infty} \frac{\epsilon}{\mathrm{NQm}} \frac{\partial}{\partial \epsilon} \mathrm{F}_{\mathrm{o}}(\epsilon) \mathrm{d} \epsilon$

And the diffusion coefficient is Do is:

$\mathrm{D}_{\mathrm{o}}=\frac{1}{3}\left(\frac{2 \mathrm{e}}{\mathrm{m}}\right)^{\frac{1}{2}} \int_{0}^{\infty} \frac{\epsilon}{\mathrm{NQ}_{\mathrm{m}}} \mathrm{F}_{\mathrm{o}}(\epsilon) \mathrm{d} \epsilon$

Where Do represent the isotropic diffusion coefficient. Thus, the mobility of the electron was depending on the momentum transfer cross section Qm and according to equation (1) then change with energy.

Calculation of the momentum transfer cross section and other inelastic cross sections using the theoretical procedure $[10,11]$ for the electron diffusion coefficients are in accordance with the experimental data at the $\mathrm{E} / \mathrm{N}$ range as seen in table 1 . The diffusion coefficient Dth was obtained through solution of the Boltzmann equation (4) using the finite difference method [12].

Table (1) The diffusion coefficient Dth for thermal electron, of CO2, He, N2, CO2 2.5\% He 45\% N2 52.5\%, CO2 $5 \%$ He $55 \%$ N2 40\%, CO2 10\% He 50\% N2 40\%, CO2 40\% He $40 \%$ N2 $20 \%$ per temperature respectively

\begin{tabular}{|c|c|c|c|c|c|}
\hline \multirow{3}{*}{$\mathrm{T}(\mathrm{oK})$} & \multicolumn{5}{|c|}{$\mathrm{E} / \mathrm{N}(\mathrm{V} . \mathrm{cm} 2)$} \\
\hline & $1 \times 10-19$ & $1 \times 10-18$ & $1 \times 10-17$ & $1 \times 10-16$ & $1 \times 10-15$ \\
\hline & \multicolumn{5}{|l|}{ Dth } \\
\hline \multirow{7}{*}{288} & 0.641205 & 0.6413157 & 0.6527003 & 55.80812 & 1125.326 \\
\hline & 962.9183 & 1030.482 & 1276.677 & 1688.517 & 1942.529 \\
\hline & 716.3343 & 926.2188 & 2055.901 & 4905.108 & 5147.747 \\
\hline & 560.6482 & 642.5728 & 1218.0570 & 2030.296 & 2949.049 \\
\hline & 422.6324 & 476.4736 & 1041.3120 & 2148.4210 & 3291.5490 \\
\hline & 292.3365 & 322.3814 & 739.5884 & 2140.4900 & 3083.4600 \\
\hline & 102.8016 & 107.5506 & 173.9630 & 2348.4300 & 3331.9950 \\
\hline \multirow{7}{*}{295} & 0.6543124 & 0.6544229 & 0.6658024 & 56.1411 & 1125.328 \\
\hline & 963.6191 & 1030.568 & 1276.729 & 1688.516 & 1942.538 \\
\hline & 721.0577 & 928.7944 & 2056.67 & 4905.084 & 5147.761 \\
\hline & 561.8684 & 643.012 & 1218.213 & 2030.268 & 2949.065 \\
\hline & 423.7426 & 476.7802 & 1041.454 & 2148.419 & 3291.539 \\
\hline & 293.1899 & 322.553 & 739.6628 & 2140.491 & 3198.516 \\
\hline & 103.1916 & 107.7229 & 174.0066 & 2348.436 & 3331.999 \\
\hline \multirow{7}{*}{300} & 0.6634301 & 0.663506 & 0.6749308 & 56.37617 & 1125.329 \\
\hline & 964.11779 & 1030.629 & 1276.765 & 1688.51 & 1942.504 \\
\hline & 724.4133 & 930.634 & 2057.221 & 4558.147 & 4727.046 \\
\hline & 562.7126 & 643.3265 & 1218.324 & 2030.267 & 2949.004 \\
\hline & 424.5057 & 477.0001 & 1041.556 & 2148.419 & 3291.563 \\
\hline & 293.772 & 322.6763 & 739.7257 & 2140.49 & 3198.507 \\
\hline & 103.4558 & 107.8423 & 174.0377 & 2348.438 & 3332.007 \\
\hline \multirow{3}{*}{355} & 0.7532429 & 0.753359 & 0.7654265 & 58.89149 & 1125.331 \\
\hline & 969.482 & 1031.27 & 1277.17 & 1688.513 & 1942.542 \\
\hline & 760.3594 & 950.8555 & 2063.277 & 4558.23 & 4727.054 \\
\hline
\end{tabular}




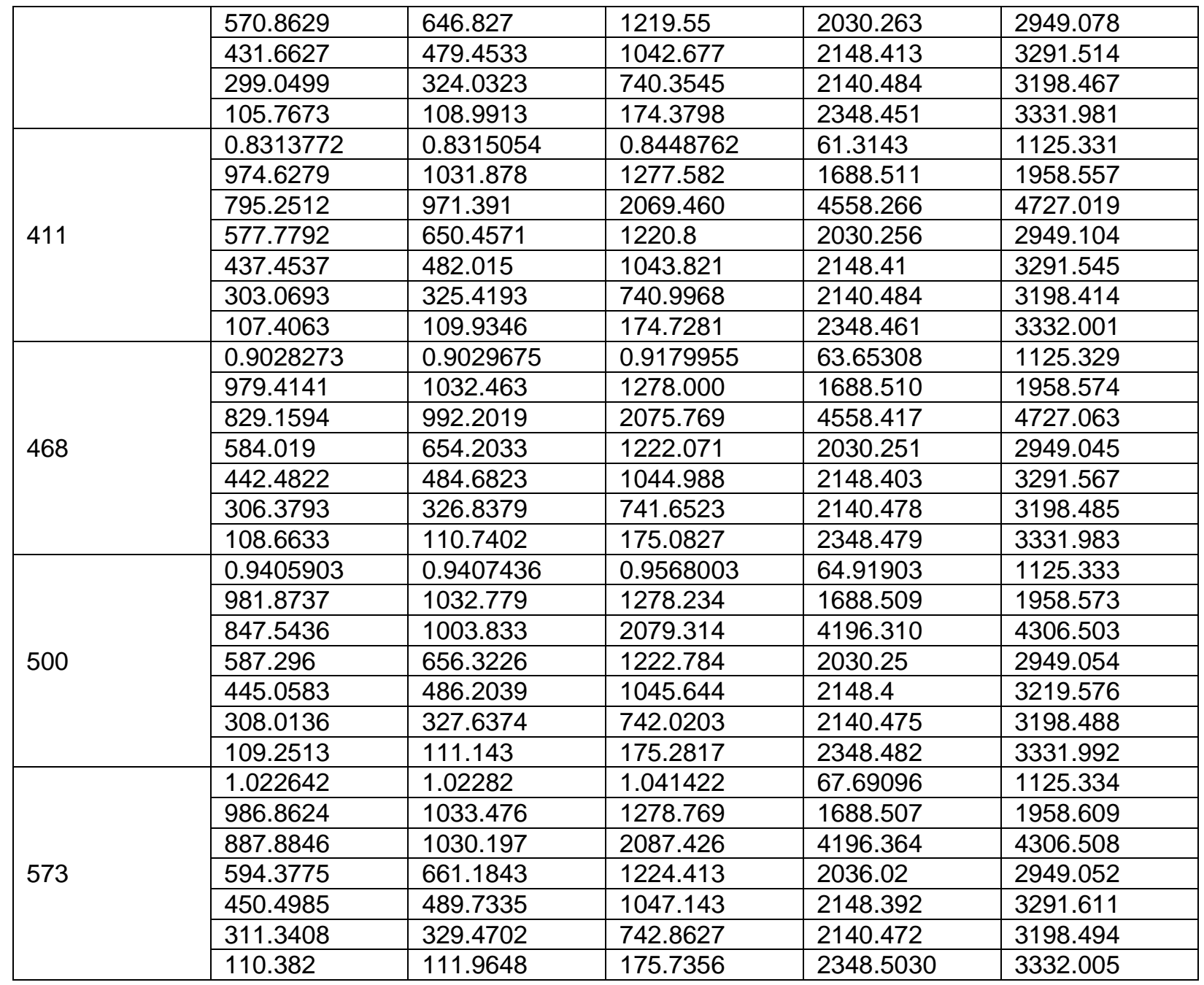

\section{Evaluation procedure of diffusion coefficient Dth:}

Through the Boltzmann equation (4) solution by finite difference method was deduced the function of the electron distribution function $\mathrm{Fo}(\epsilon)[13,14]$, then obtained diffusion of the thermal electrons for single gases, such as $\mathrm{CO} 2, \mathrm{He}, \mathrm{N} 2$ gases and their as seen in table (1).

\section{$\mu$ Nth calculation:}

When the diffusion coefficients Dth where calculated after solution the Boltzmann equation (4) whereupon, Dth values were substituted into equation (2), in addition to values of the temperatures $(288,295,300,355$, $411,468,500$ and 573$)$, then, obtained the $\mu$ Nth values need as shown in Figures (1-6).

\section{Results and Discussion:}

The changing of the momentum transfer cross section $\Theta m(\epsilon)$ with energy $\epsilon$ was permit to find the transport parameter Dth $[15,16]$. The calculated results of Boltzmann equation solution to obtain the parameter Dth as shown in table (1), its permitted to determine the $\mu$ Nth values at $(1 \times 10-19-5 \times 10-15) \mathrm{Vcm} 2$ for $\mathrm{CO} 2, \mathrm{He}$, $\mathrm{N} 2$, and its mixtures, these values were compared with experimental data [10,13].

From figure (1) it's obvious that, the electron component $\mu$ Nth as a function for the percentage of electric field strength to the whole gas number density of $E / N$ of CO2. The value of $\mu$ Nth does not depend on E/N for low values from $1 \times 10-19$ to $8 \times 10-17 \mathrm{Vcm} 2$, and becomes zero at $1 \times 10-16 \mathrm{Vcm} 2$. The values of $\mu \mathrm{Nth}$ increased rapidly until $3 \times 10-16 \mathrm{Vcm} 2$, then at $2 \times 10-16 \mathrm{Vcm} 2$ the values of $\mu \mathrm{Nth}$ will be constant during increasing of temperature, but in the case of He gas, the value of $\mu \mathrm{Nth}$ will be constant and undependable on temperature. From figure (3) it obvious that the value of $\mu$ Nth increase gradually with $E / N$. Figures (4-7) were show that the increase of $\mathrm{CO} 2$ percentage in the mixture will reduces the value of $\mu \mathrm{N}$ th and $\mathrm{E} / \mathrm{N}$ to zero and similar to 


\section{5 | Nisaan Saud ORAIBI}

figure (1) which is the case of unique gas and $\mathrm{CO} 2$ the values of $\mu$ Nth will increased with $\mathrm{E} / \mathrm{N}$ from $1 \times 10-19$ to $2 \times 10-17 \mathrm{Vcm} 2$ and will be increased rapidly from $2 \times 10-17$ to $1 \times 10-15 \mathrm{Vcm} 2$, but, after these values, the behavior of $\mu \mathrm{Nth}$ going to be constant. from above its clear that all figures in agreements with practical values [4]. The current values are sufficiently taken at low values of E/N which makes the electron swarm approach to thermal equilibrium with gas molecules. The values of $\mu \mathrm{Nth}$ are imaginary and undependable and in contrast with the value of $\mathrm{E} / \mathrm{N}$, making an extrapolation to zero $\mathrm{E} / \mathrm{N}$ an accurate procedure. The values of $\mu$ Nth has been obtained and shown in figures (8-12) are a function of temperature, hence, reveals a contrast with it and compared with reference [4]. The values of $\mu$ Nth current work reveals a coincidence with results in references [2, 4, and 10] for the familiar temperature range (288-573) oK as shown in figure (13). From figures above its known that when $\mathrm{E} / \mathrm{N}$ values are low, then the values of $\mu \mathrm{Nth}$ becomes coincidence due to ionizing small molecules particles, conversely, the values of $\mu$ Nth will be in contrast if the temperature increased $T$, due to high molecules ionization, and this agrees the change of $\mu \mathrm{Nth}$ with $\mathrm{T}$ derived from reference [4].

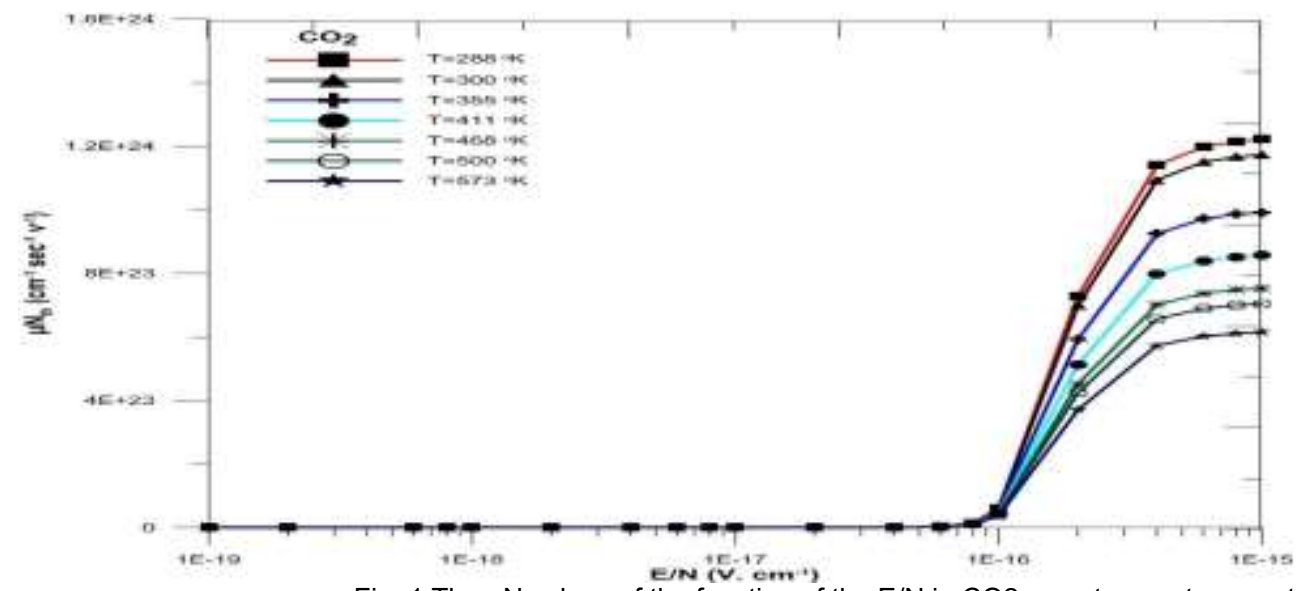

Fig. 1 The $\mu \mathrm{N}$ values of the function of the $\mathrm{E} / \mathrm{N}$ in $\mathrm{CO} 2$ gas at many temperatures.

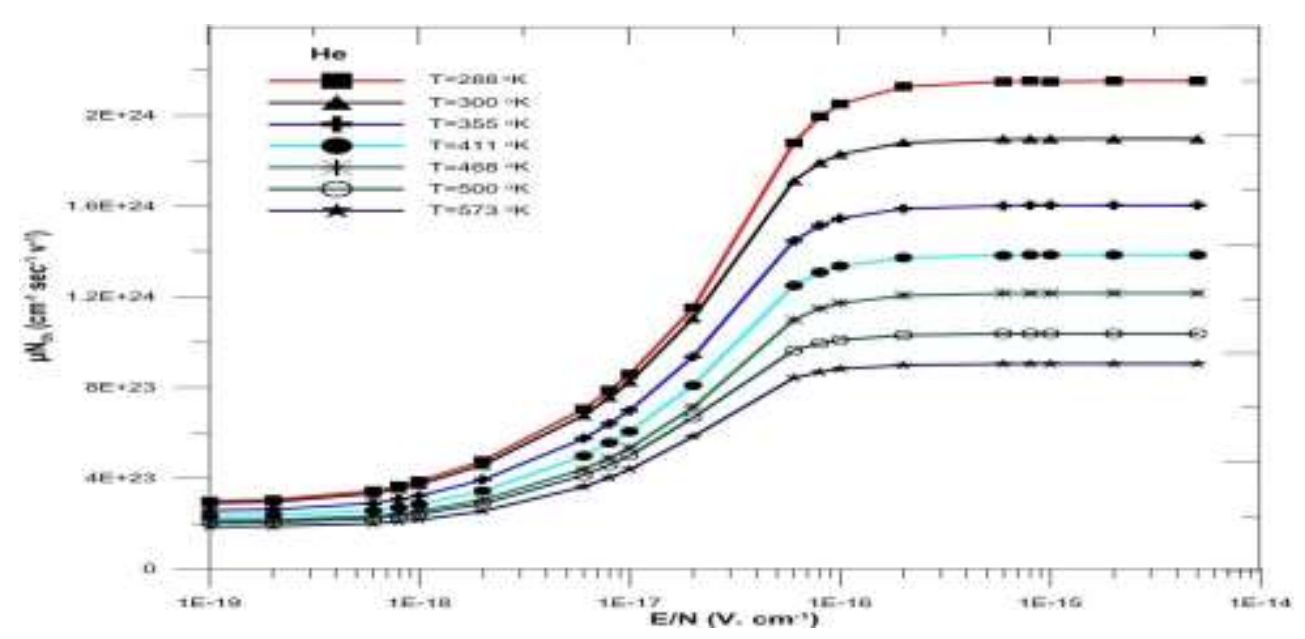

Fig. 2 The $\mu \mathrm{N}$ values of the function of the $\mathrm{E} / \mathrm{N}$ in He gas at many temperatures.

December 2020, Volume 2, Issue 4

p. 31-41 


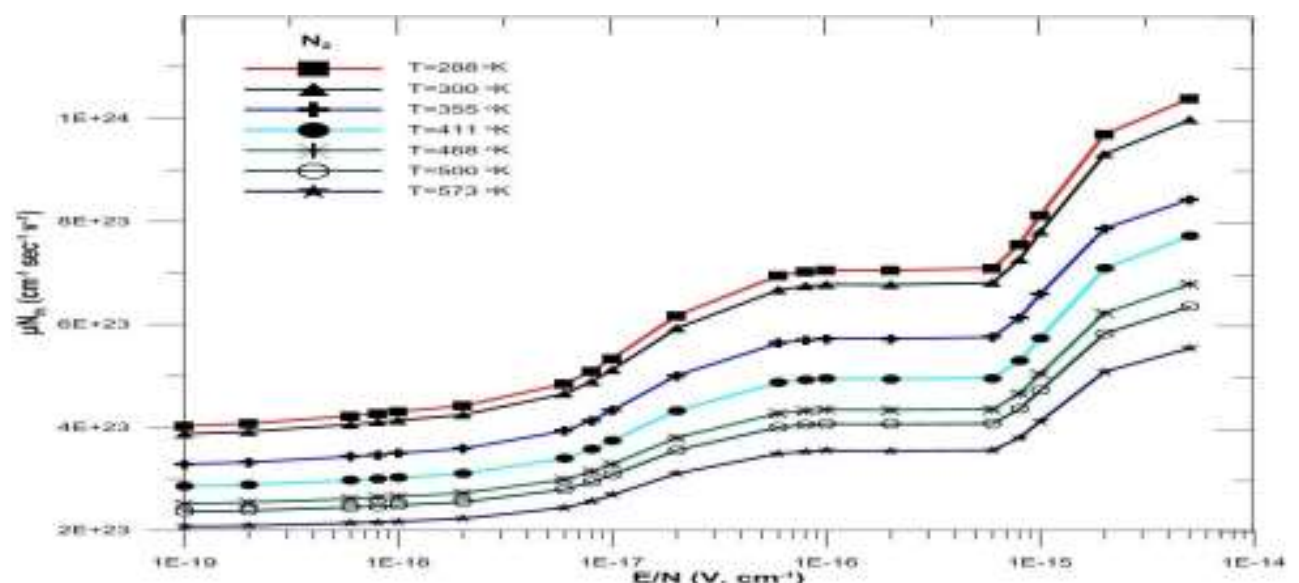

Fig. 3 The $\mu \mathrm{N}$ values of the function of the $\mathrm{E} / \mathrm{N}$ in $\mathrm{N} 2$ gas at many temperatures.

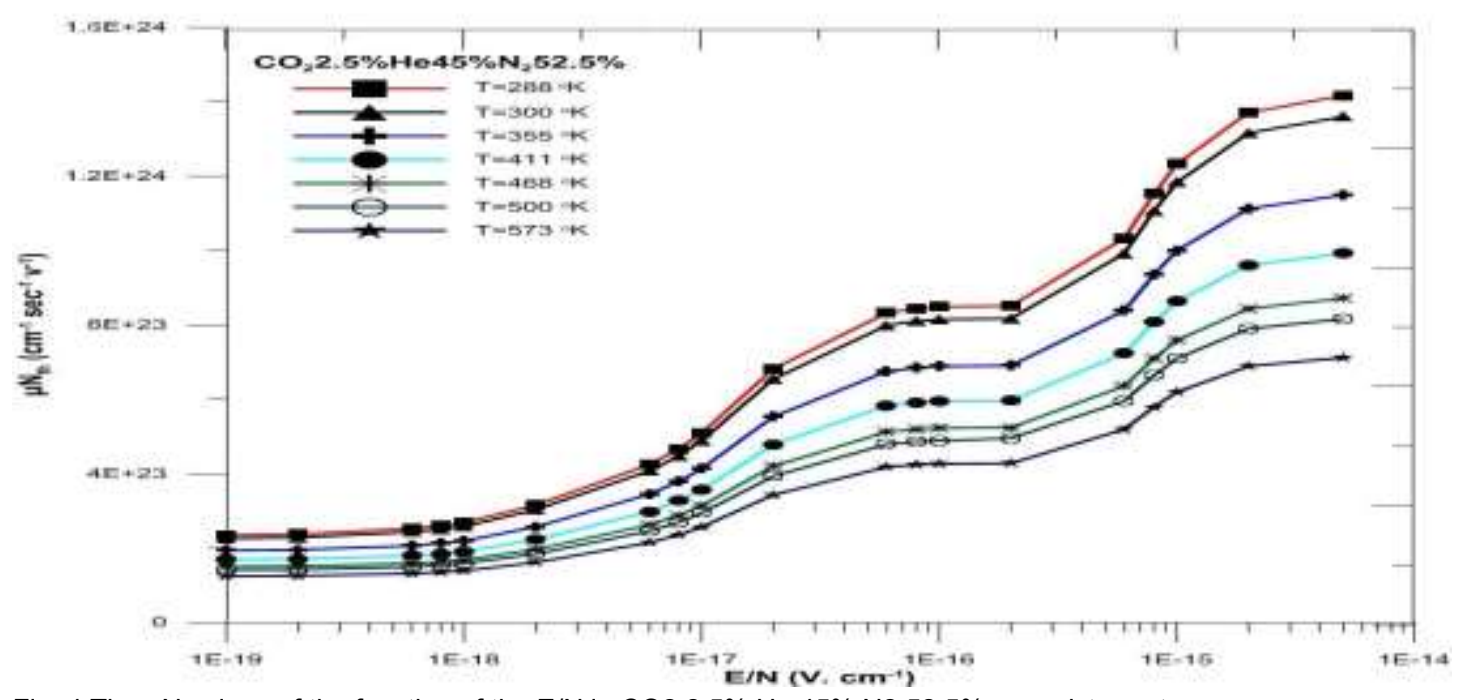

Fig. 4 The $\mu \mathrm{N}$ values of the function of the $\mathrm{E} / \mathrm{N}$ in $\mathrm{CO} 22.5 \% \mathrm{He} 45 \% \mathrm{~N} 252.5 \%$ gas mixture at many temperatures.

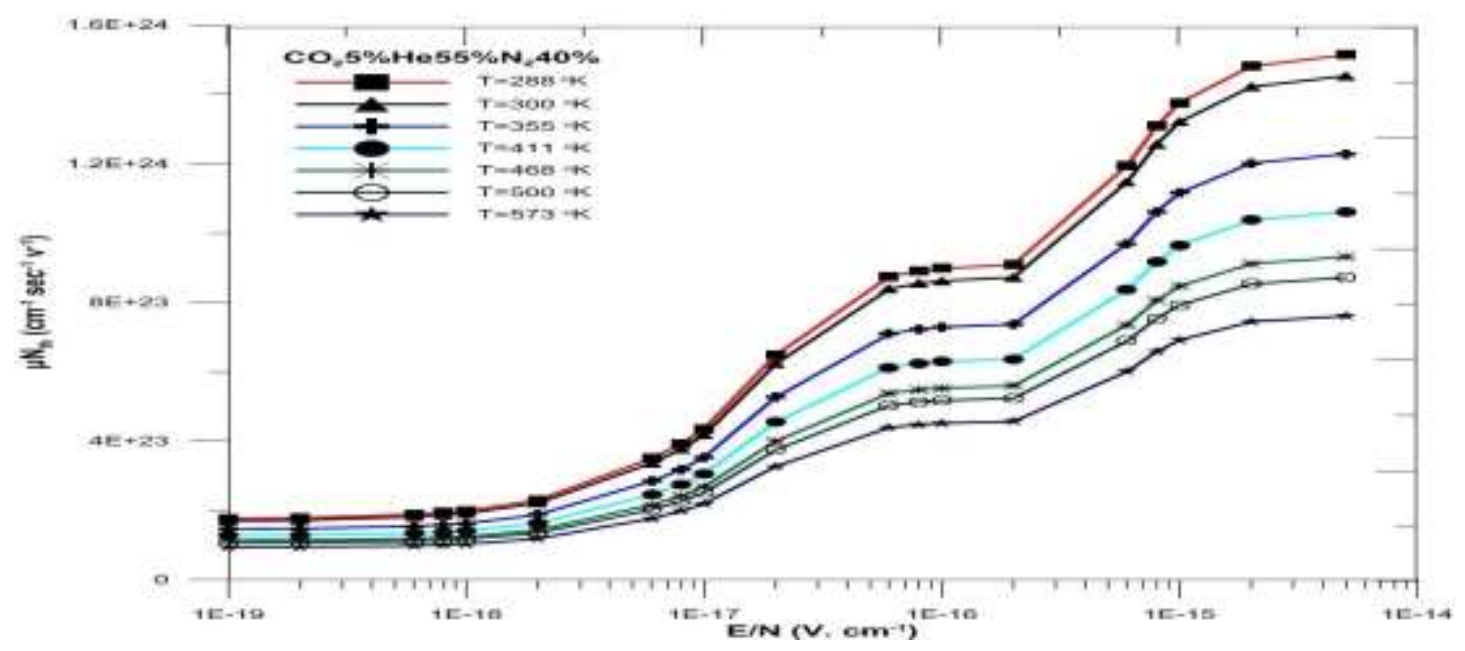

Fig. 5 The $\mu \mathrm{N}$ values of the function of the $\mathrm{E} / \mathrm{N}$ in $\mathrm{CO} 25 \% \mathrm{He} 55 \% \mathrm{~N} 240 \%$ gas mixture at many temperatures. 


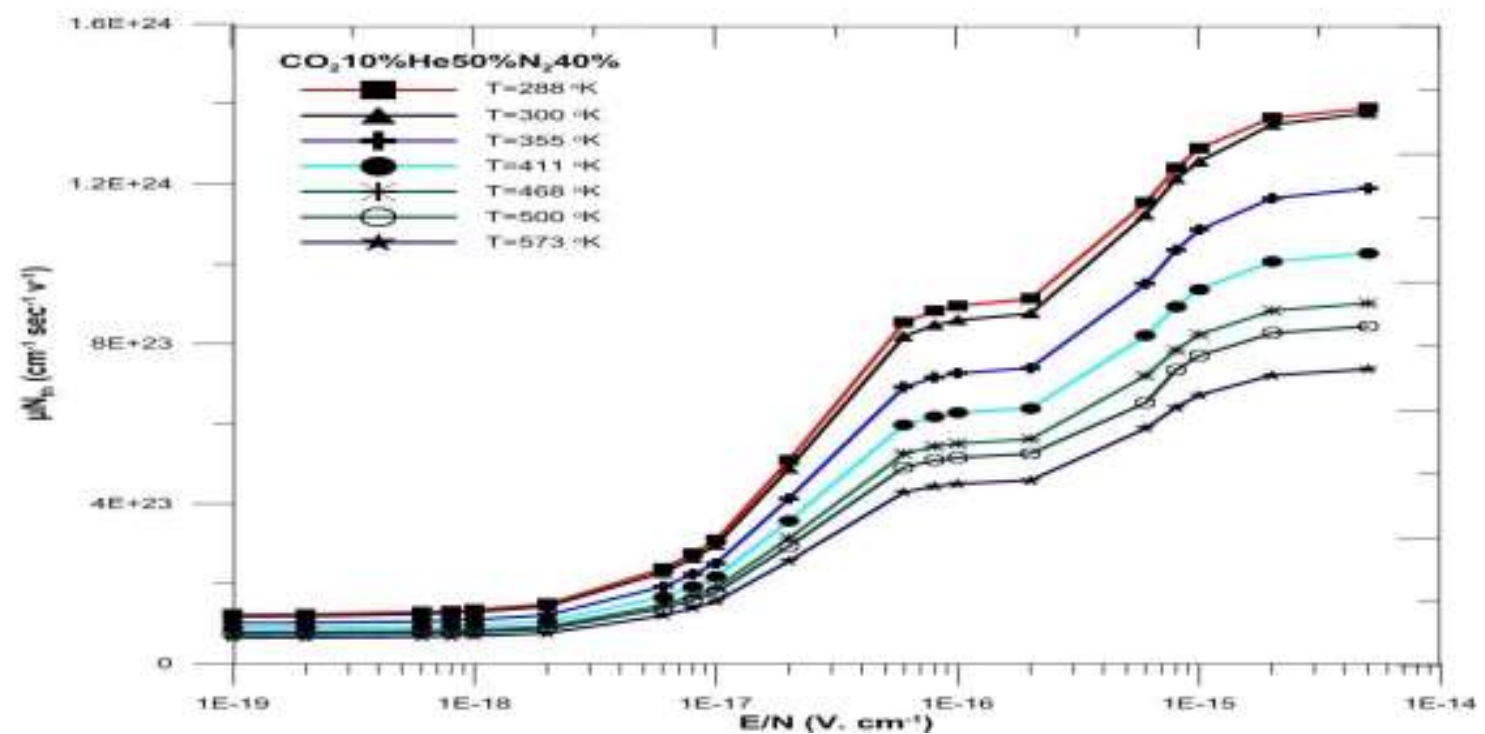

Fig. 6 The $\mu \mathrm{N}$ values of the function of the $\mathrm{E} / \mathrm{N}$ in $\mathrm{CO} 210 \% \mathrm{He} 50 \% \mathrm{~N} 240 \%$ gas mixture at many temperatures.

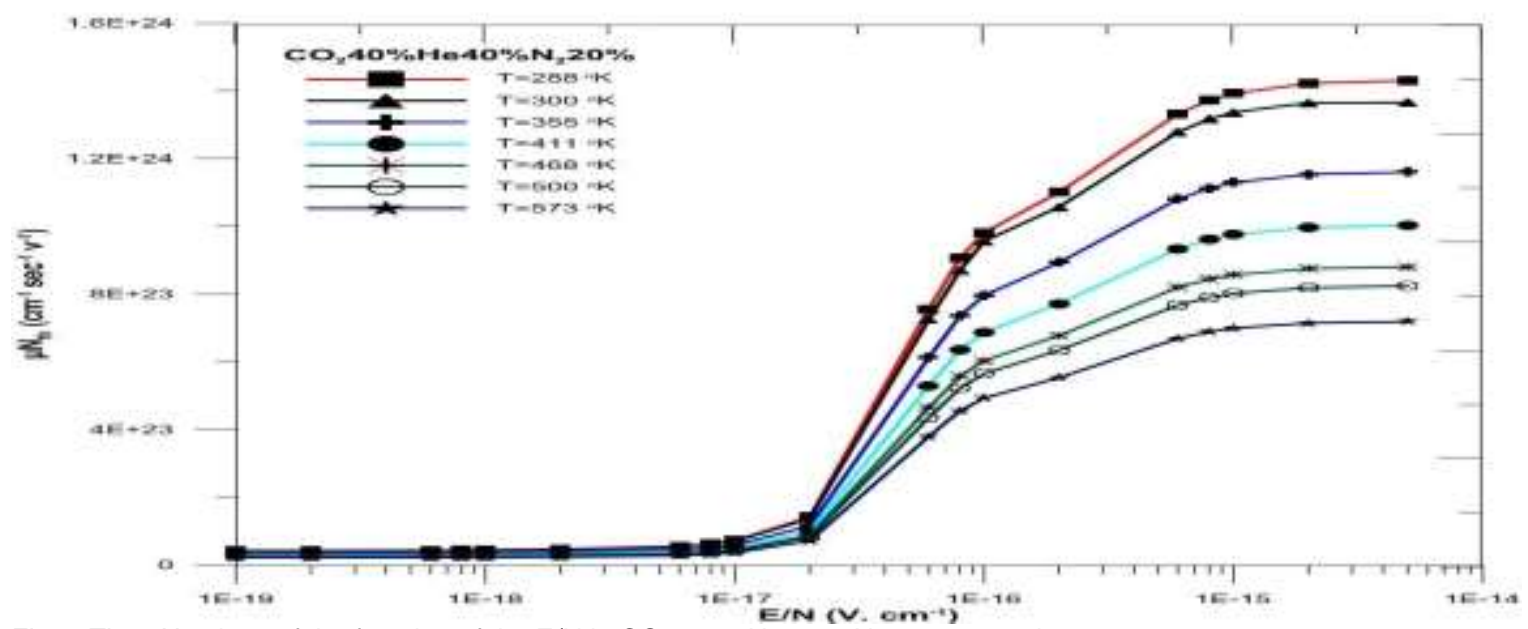

Fig. 7 The $\mu \mathrm{N}$ values of the function of the $\mathrm{E} / \mathrm{N}$ in $\mathrm{CO} 240 \% \mathrm{He} 40 \% \mathrm{~N} 220 \%$ gas mixture at many temperatures.

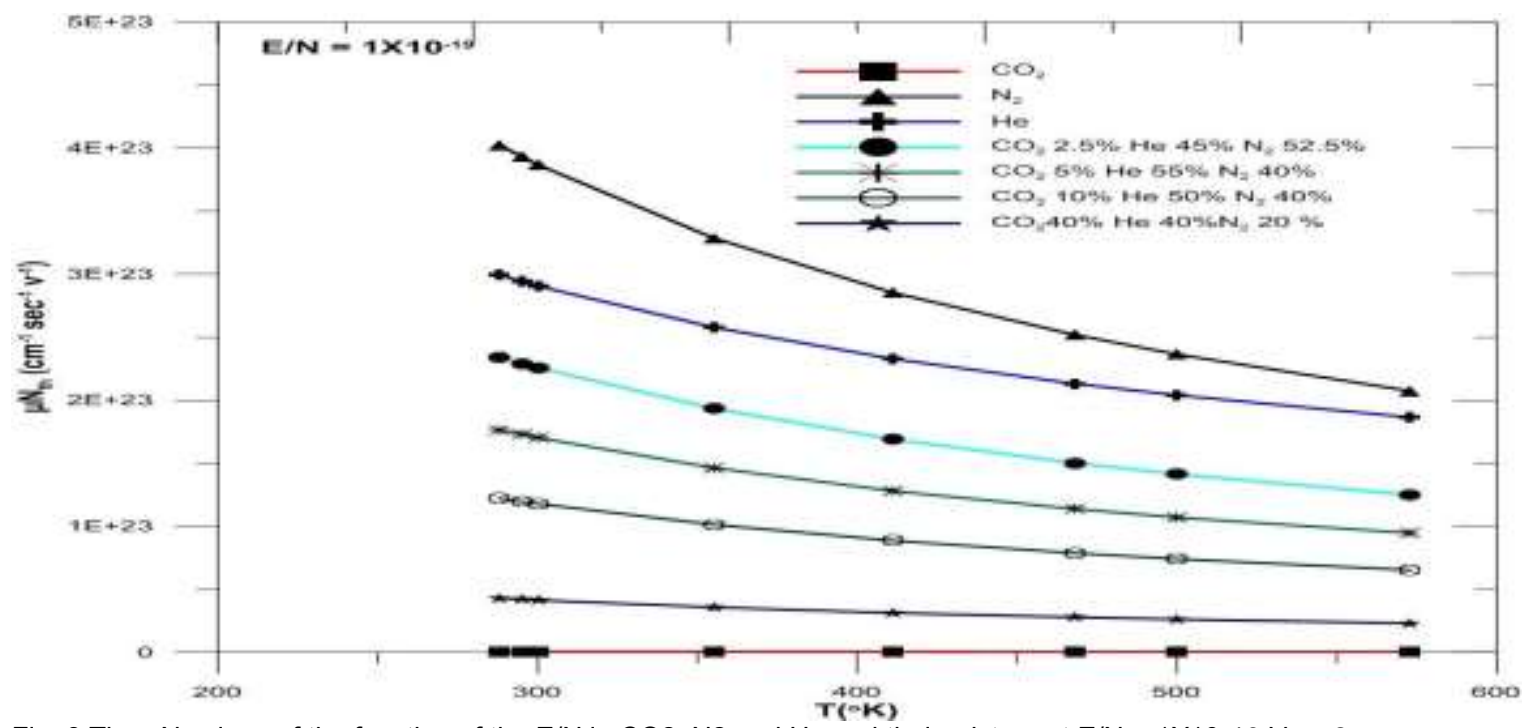

Fig. 8 The $\mu \mathrm{N}$ values of the function of the $\mathrm{E} / \mathrm{N}$ in $\mathrm{CO} 2, \mathrm{~N} 2$ and $\mathrm{He}$ and their mixture at $\mathrm{E} / \mathrm{N}=1 \mathrm{X} 10-19 \mathrm{~V} . \mathrm{cm} 2$ 


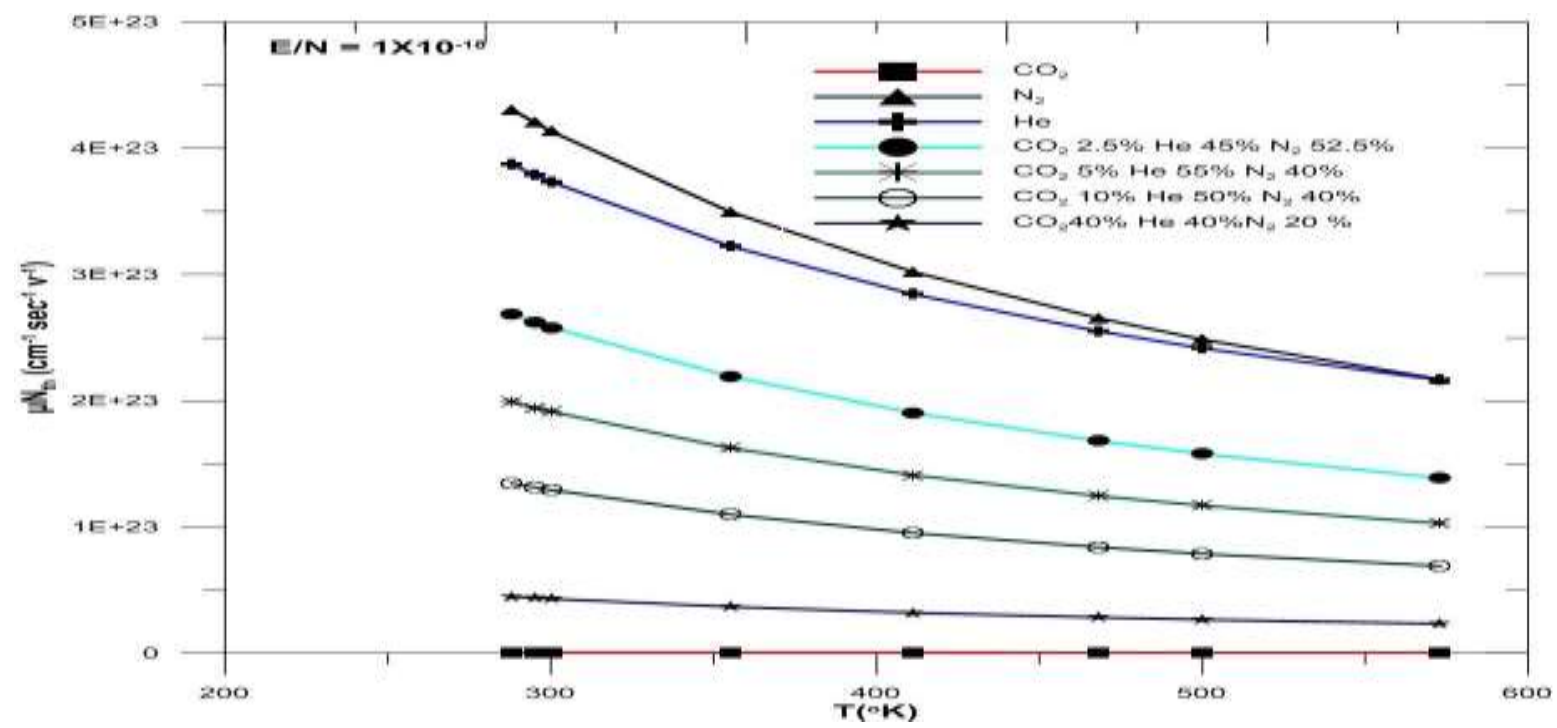

Fig. 9 The $\mu \mathrm{N}$ values of the function of the $\mathrm{E} / \mathrm{N}$ in $\mathrm{CO} 2, \mathrm{~N} 2$ and $\mathrm{He}$ and their mixture at $\mathrm{E} / \mathrm{N}=1 \mathrm{X} 10-18 \mathrm{~V} . \mathrm{cm} 2$

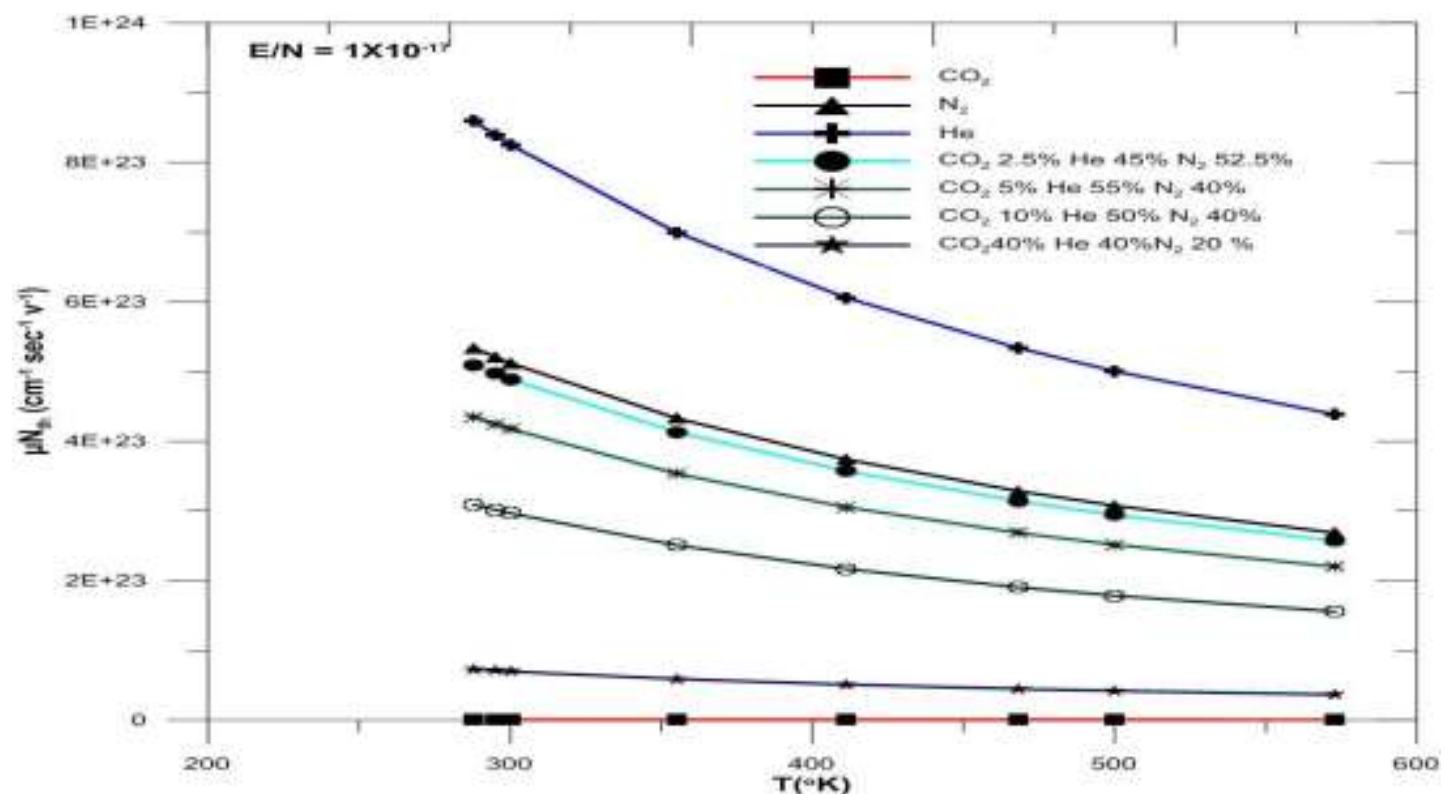

Fig. 10 The $\mu \mathrm{N}$ values of the function of the $\mathrm{E} / \mathrm{N}$ in $\mathrm{CO} 2, \mathrm{~N} 2$ and $\mathrm{He}$ and their mixture at $\mathrm{E} / \mathrm{N}=1 \mathrm{X} 10-17 \mathrm{~V} . \mathrm{cm} 2$ 


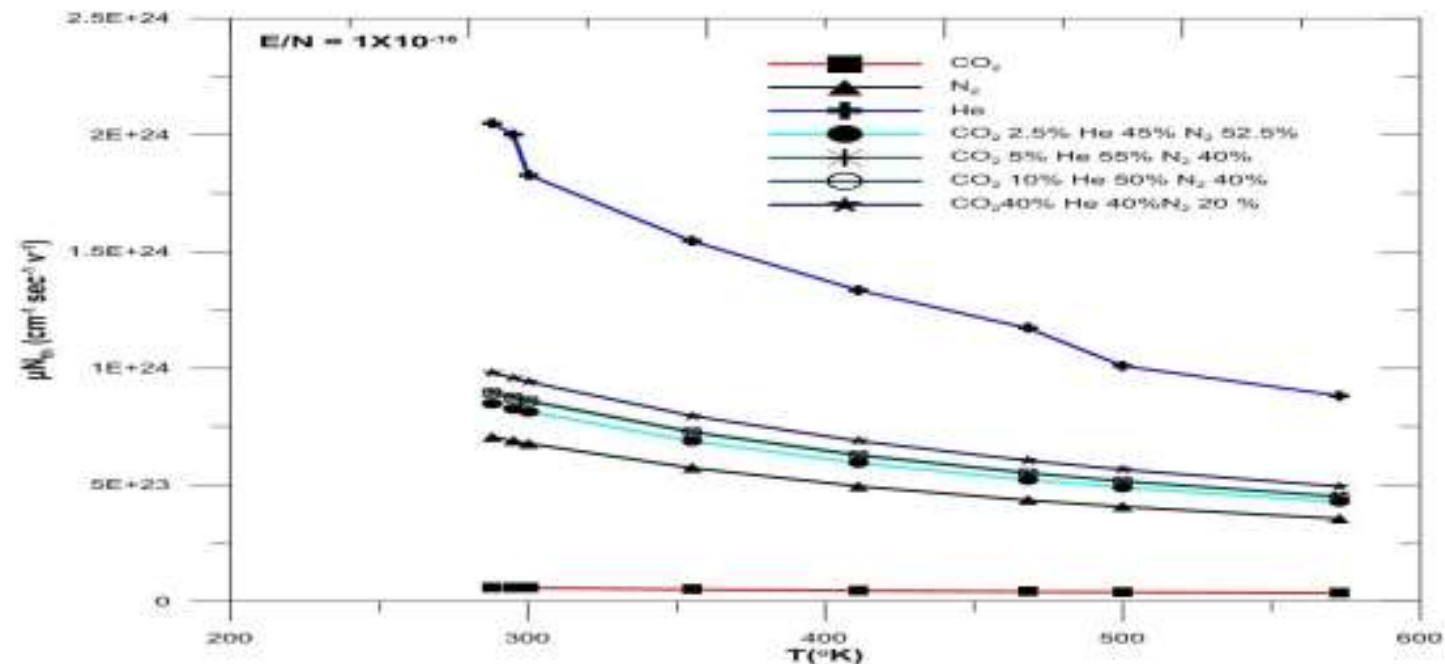

Fig. 11 The $\mu \mathrm{N}$ values of the function of the $\mathrm{E} / \mathrm{N}$ in $\mathrm{CO} 2, \mathrm{~N} 2$ and $\mathrm{He}$ and their mixture at $\mathrm{E} / \mathrm{N}=1 \mathrm{X} 10-16 \mathrm{~V} . \mathrm{cm} 2$

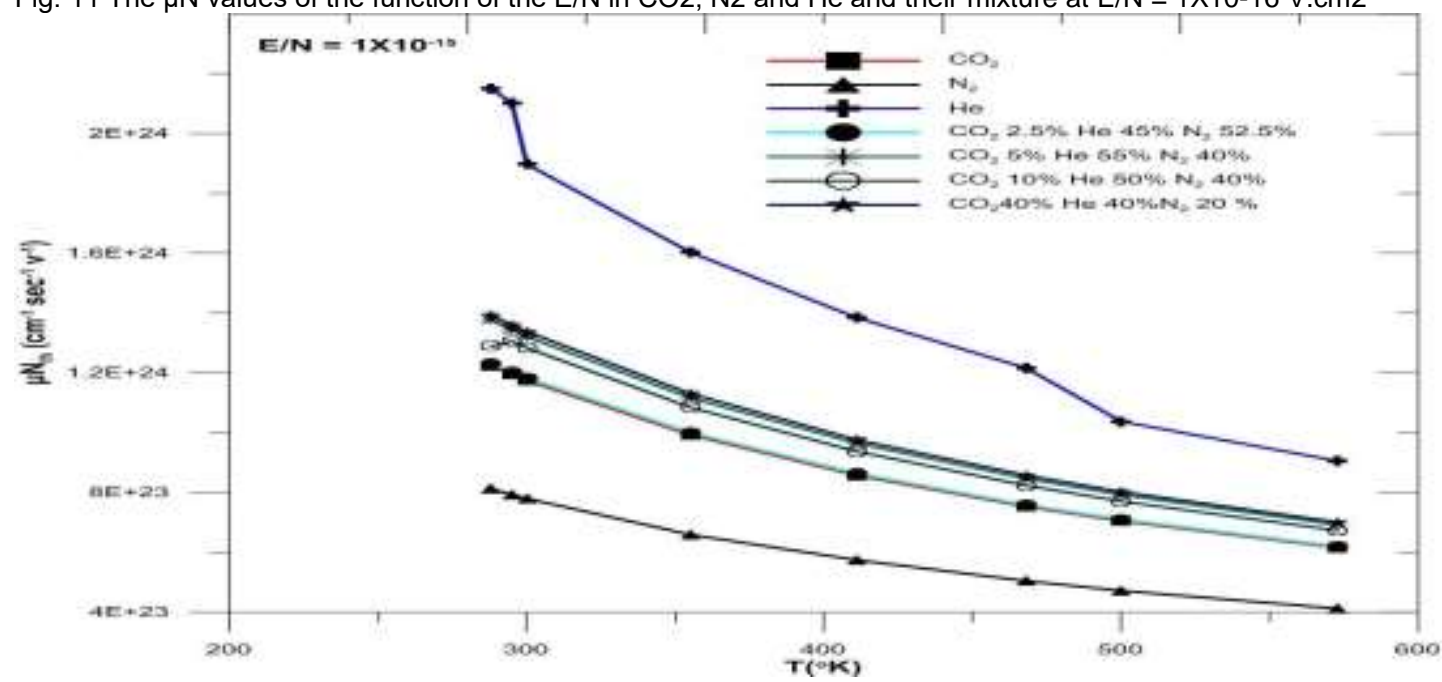

Fig. 12 The $\mu \mathrm{N}$ values of the function of the $\mathrm{E} / \mathrm{N}$ in $\mathrm{CO} 2, \mathrm{~N} 2$ and $\mathrm{He}$ and their mixture at $\mathrm{E} / \mathrm{N}=1 \mathrm{X} 10-15 \mathrm{~V} . \mathrm{cm} 2$ 


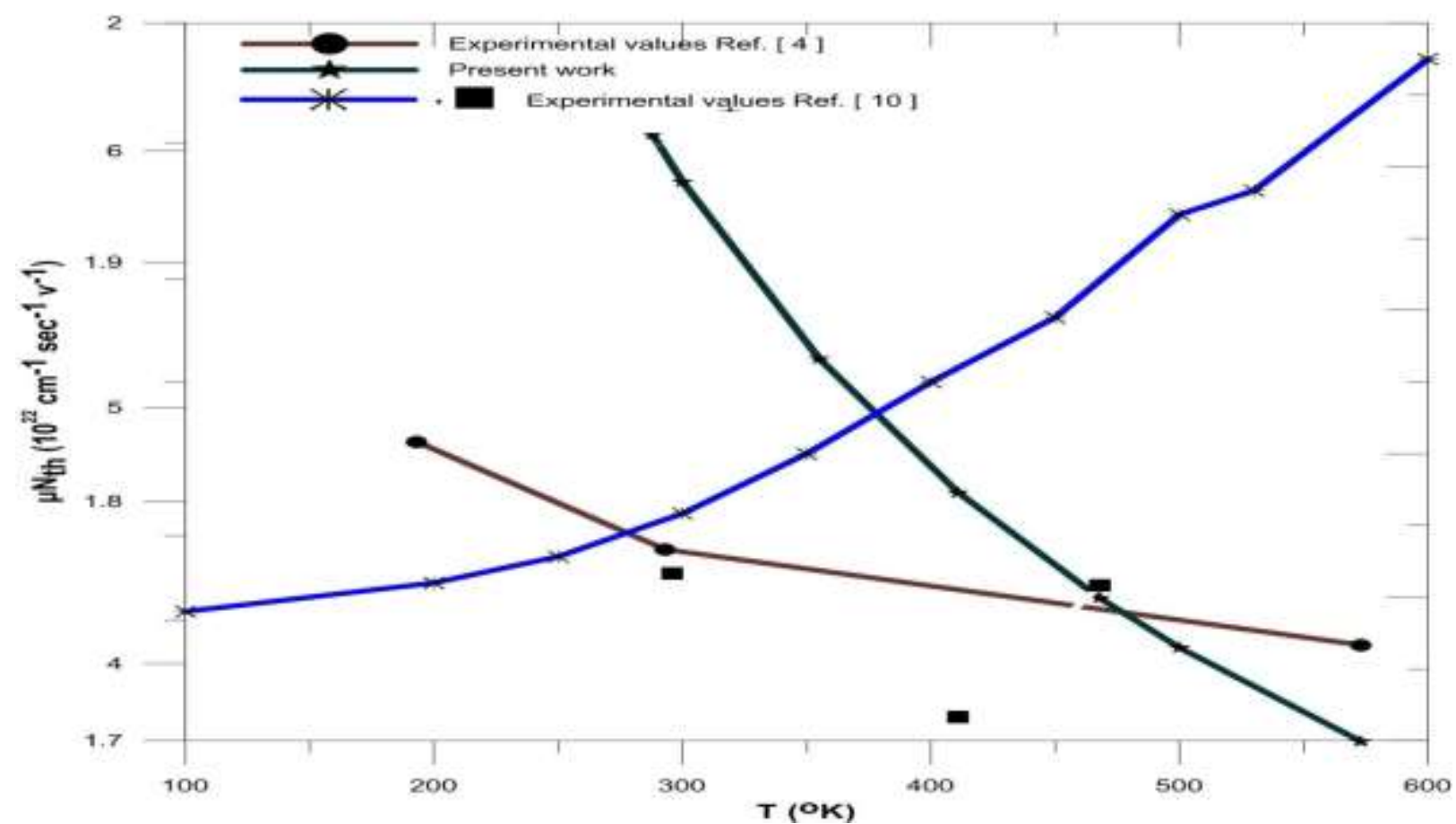

Fig. 13 comparison between the present work for the values of the $\mu \mathrm{Nth}$ versus gas temperature of electrons in $\mathrm{CO} 2$ gas with the experimental values

\section{Conclusion:}

The present result investigates the $\mu$ Nth change with gases temperatures which was deduced by [2] and extend the temperature range to $573 \mathrm{oK}$. The $\mu$ Nth versus T change had been serve as rigorous check on the derived momentum transfer cross sections. The value of $\mu \mathrm{Nth}$ at $573 \mathrm{oK}$ is not congenial with the momentum transfer cross section deduced using 239 oK data [15].

The indicated references reveals to significant levels of impurities were not introduced by outgassing of the cell, the associated ballast, etc. The purification procedure is found to be necessary to avoid the values of the measured time constant increasing over the initial period of the data accumulation.

There is no dependence on gas pressure. The values of $\mu \mathrm{N}$ th decrease with temperature at $\mathrm{E} / \mathrm{N}>1 \times 10-17 \mathrm{~V}$ $\mathrm{cm} 2$.

\section{References:}

Boker, C.J., Hall, D.R. and Davies, A.R.: Electron Energy Distributions, Coefficients and Electron Excitation Rates for RF Excited CO2 Laser. J. Phys. D: Appl. Phys. 17(4), 1597-1606 (1984)

Chachereau, A., Rabie, M., and Franck C.: Electron Swarm Parameters of the Hydrofluroolefine HFO1234ze. Plasma Sources Science and Technology. 25(4), 045005 (2016)

Donkol, Z. and Dyatko, N.: First principles particle simulation and Boltzmann Equation Analysis of Negative Differential Conductivity and Transient Negative Mobility Effects in Xenon. Eur. Phys. J. D. 70, 135146, (2016)

Duzkaya, H., Tezcan, S.S.: Boltzmann Analysis of Electron Swarm parameter in CHF3+CF4 Mixture, Turk J of Elec Eng \& Comp Sci. 27, 615-622 (2019)

Elford, M.T. and Haddad, G.N.: The drift Velocity of the Electrons in Carbon Dioxide at Temperatures between 193 and 573 oK. Aust. J. Phys. 33, 517-30 (1980)

Engelhardt, A.G., Phelps A.V., and Risk C.G.: Determination of Momentum Transfer and Inelastic Collision Cross Sections for Electrons in Nitrogen Using Transport Coefficients. Phys. Rev. 135(6A), A1566A1574 (1964)

Frost, L.S and Phelps, A.V.: Momentum Transfer Cross Sections for Slow Electrons in $\mathrm{He}, \mathrm{Ar}$, $\mathrm{Kr}$ and $\mathrm{Xe}$ from Transport Coefficients. Phys. Rev.136(6A), A1538 (1964)

Frost, L.S and Phelps, A.V.: Rotational Excitation and Momentum Transfer Cross Sections for Thermal Electrons H2 and N2 from Transport Coefficients. Phys. Rev. 127(5), 1621-1633 (1962)

Kucukarpaci, H.N. and Lucas, L.: Simulation of Electron Swarm Parameters in Carbon Dioxide and Nitrogen for High E/N. J. Phys. D: Appl. Phys. 12(12), 2123-2138 (1979) 


\section{1 | Nisaan Saud ORAIBI}

$\mathrm{Li}, \mathrm{X}$., Guo, X., Zhao, H. and Jia, S.: Predication of the critical reduced electric field strength for carbon dioxide and its mixtures with copper vapor from Boltzmann analysis for a gas temperature range of $300 \mathrm{~K}$ to $4000 \mathrm{~K}$ at $0.4 \mathrm{MPa}$, J. of Appl. Phys. 117, 143302 (2015)

Nakamura, Y. and Lucas, J.: Electron Drift Velocity and Momentum Cross Section in Mercury, Sodium, and Thallium Vapors. II. Theoretical. J. Phys. D: Appl. Phys. 11(3), 337-345 (1978)

Pack, J.L and Phelps, A.V.: Drift Velocities of Slow Electrons in Helium, Neon, Argon, Hydrogen and Nitrogen. Phys. Rev. 121, 798 (1961)

Pack, J.L., Voshali, R.E. and Philips A.V.: Drift Velocity of Slow Electrons in Krypton, Xenon, Deuterium, Carbon Monoxide, Carbon Dioxide, Water Vapor, Nitrous Oxide and Ammonia. Phys. Rev. 127(6), 2084-2089 (1962)

Rockwood, S., Green, A.: Numerical Solutions of the Boltzmann Transport Equation. Computer Physics Communications. 19(3), 337-393 (1980)

Vass, M., Korolov, I., Loffhogen, D, Pinhao, $\mathrm{N}$ and Donko, Z.: Electron Transport parameters in CO2: Scanning Drift Tube Measurements and Kinetic Computations. Plasma Sources sci Technol. 26(6) 065007, (2017)

Yousfi, M., Urquijo, J., Juarez, A., Basurto, E. and Hernandez-Avila J.L.: Electron Swarm Coefficients in CO2-O2 Mixtures. IEEE Transactions on Plasma Science. 37(6), 764-772 (2009) 